\section{Palliative care: \\ Definition of euthanasia}

To the Editor: Euthanasia is defined as 'conduct that brings about an easy and painless death for persons suffering from an incurable or painful disease or condition. ${ }^{[1]}$ Active euthanasia is the intentional killing of a person suffering from an incurable disease, and fulfils the legal criteria for murder. There is intent, causation, a human is the victim, and the act, whether by omission or commission, is unlawful. Motive, albeit the altruistic desire to relieve unnecessary suffering in the face of futility, is irrelevant to criminal intent. ${ }^{[2]}$ The term passive euthanasia includes withholding extreme medical measures or removing life support in the presence of futile or non-beneficial treatment. McQuoid-Mason ${ }^{[2]}$ outlines the reason why, in the eyes of the law, passive euthanasia is not a criminal offence, and withholding or withdrawing life-sustaining treatment or administering sufficient analgesia and sedation during the latter cannot be construed as murder. Of the four legal prerequisites for the definition of murder, namely intent, causation, a human victim and contravention of the law, only the last-mentioned is not fulfilled and spares the doctor from a conviction. Although reassuring to those working in critical care, where withholding or withdrawing support is a fact of life (or death), the fact that only one component of the legal definition spares us from being labelled criminals is somewhat disconcerting. We would argue that in addition to the lack of unlawfulness, neither intent nor causation applies, and furthermore that the term 'passive euthanasia' is an oxymoron and should be abandoned.

In the situation of withholding or withdrawing treatment, which hastens death, the legal concept of eventual intent applies whereby the perpetrator does not mean to kill the person but does foresee death as a consequence. ${ }^{[2]}$ We contend that death arises directly as a consequence of the underlying disease process and the inability of the patient to maintain homeostasis, and indirectly as the result of withdrawal of support. In fact McQuoid-Mason ${ }^{[1]}$ defines passive euthanasia as 'aiming at preventing the prolonging of death by allowing an irreversible fatal underlying illness to kill the patient through withholding or withdrawing treatment', implying thereby that the disease and not the actions of the doctor causes death. There is a major difference between intentional killing, albeit out of altruism, and allowing death to occur as a direct consequence of the inciting disease or injury in the presence of non-beneficial treatment.

The same argument pertains to causation, where legally the underlying disease is not considered as a new intervening cause and the cause of death is regarded as the final event, such as withholding or withdrawing therapy. According to McQuoid-Mason's definition of passive euthanasia, it is the underlying illness that is responsible for death. Furthermore, part 1 of paragraph 77 in Section G1 of the Notice of Death/Still Birth clearly specifies that the immediate cause of death must be documented as the final disease or condition resulting in death. This is in direct conflict with legal causation if treatment has been withheld or withdrawn. Must we therefore complete the immediate cause of death as withdrawal of therapy and conditions leading to the immediate cause as non-beneficial treatment?

That the legal stance of causation is contentious is illustrated by the following not uncommon scenario in South Africa. Consider two patients with traumatic brain injury and a large extradural haematoma, one in a remote rural area and the other with immediate access to a neurosurgical unit. The former dies before transfer to definitive care, and the latter after a craniotomy and evacuation but when further treatment is deemed non-beneficial and support is therefore withdrawn. Both die as a direct consequence of their injury. Why therefore is the act of withdrawal regarded as causation, thereby changing the entire legal perspective?

Murder cannot be defined in active or passive terms and, if synonymous by definition, neither can euthanasia. The term passive euthanasia is paradoxical, serves only to confuse, and should be abandoned. In the presence of futility, withholding or withdrawing therapy and administering sufficient doses of analgesia and sedation to ensure comfort is humane and acceptable practice. ${ }^{[3]}$ We propose that there should be only a single definition of euthanasia, namely an act of omission or commission remote from the normal standard of care with the specific intent of causing death.

\section{J J Muckart}

Department of Surgery, Nelson R Mandela School of Medicine, College of Health Sciences, University of KwaZulu-Natal, Durban, South Africa

davidmuc@ialch.co.za

\section{Dean Gopalan}

Department of Anaesthesiology, Nelson R Mandela School of Medicine, College of Health Sciences, University of KwaZulu-Natal, Durban, South Africa 


\section{Timothy Hardcastle}

Department of Surgery, Nelson R Mandela School of Medicine, College of Health Sciences, University of KwaZulu-Natal, Durban, South Africa

\section{Eric Hodgson}

Department of Anaesthesiology, Nelson R Mandela School of Medicine, College of Health Sciences, University of KwaZulu-Natal, Durban, South Africa

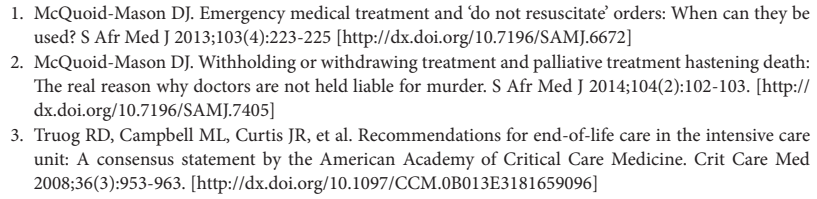

3. Truog RD, Campbell ML, Curtis JR, et al. Recommendations for end-of-life care in the intensive care unit: A consensus statement by the American Academy of Critical Care Medicine. Crit Care Med 2008;36(3):953-963. [http://dx.doi.org/10.1097/CCM.0B013E3181659096]

Prof. McQuoid-Mason responds: I can understand the somewhat emotional response to my article, illustrated by the sentence that only one component of the legal definition spares us from being labelled criminals. The real reason doctors are not held legally liable for murder when they withdraw or withhold treatment in futile cases, or hasten death through the prescription of certain drugs, is because their conduct is not unlawful - not because they do not intend the patient to die or did not cause the death of the patient.

As I said in my article, ${ }^{[1]}$ all four elements for murder (the element referring to a human being is not usually in dispute) have to be satisfied - if the unlawfulness element is missing, there is no crime.

This is not unusual for other areas of medical practice. For instance, cutting a person open during an operation is a serious assault (the surgeon causes injury to the patient's body), but it is not unlawful if the patient consented to the procedure, or it if it is an emergency situation where the patient is unable to give consent.

Muckart et al's contention that 'in addition to the lack of unlawfulness, neither intent nor causation applies' does not hold in terms of the law. Surely a doctor who orders that life support treatment is withheld or withdrawn, or prescribes a drug that lessens a person's life expectancy, knows that their omission or conduct will hasten the patient's death? Legally this knowledge amounts to eventual intention. Likewise, death will follow either immediately or later, the underlying illness or injury taking over, and the conduct of the doctor contributes to the death of the patient by allowing such condition to take over. This satisfies the legal requirement of causation for the reasons set out in the article.

The suggestion that there 'is a major difference between intentional killing, albeit out of altruism, and allowing death to occur as a direct consequence of the inciting disease or injury in the presence of nonbeneficial treatment' is recognised by the law, which states that such conduct is not unlawful - even though the other elements of murder may be present.

The concern about part 1 of paragraph 77 in Section $G$ of the Notice of Death/Still Birth could be met by adopting what was quoted from Mason and McCall Smith at the end of my article: 'Lawful withdrawal of life support systems which were necessitated by [the disease].[2] This would be the technically accurate manner of recording the death - with suitable adjustments for the nature of the injury or illness. However, it may be that the current practice is acceptable to the Registrar of Births and Deaths and the other relevant authorities.

The example of the two cases of patients with traumatic brain injury and a large extradural haematoma 'compares apples with oranges. The death of the patient in the remote rural area 'before transfer to definitive care' may be directly due to the injuries without any intervention by healthcare professionals, unless the death was due to some negligent act or omission by them, so the latter did not cause the death. In the case of the patient who is given 'immediate access to a neurosurgical unit', the healthcare professionals concerned have placed the patient on life support to keep him/her alive. When they withdraw the support they hasten the death of the patient because further treatment is futile, but their conduct is not unlawful. The 'legal perspective' does not change, because in both situations the death may be lawful.

I agree that 'passive euthanasia' is an oxymoron, for the reasons set out in the article, but it is a widely used term for lawful euthanasia. The definition of euthanasia suggested by Muckart et al. fails to deal with the question of causation and the objectives aimed at ending pain or suffering. However, there is some merit in adopting an amended version of the current definition of 'active euthanasia' as a definition of 'euthanasia' proper, without subdividing it into 'active' and 'passive.' Thus, the definition could read: 'Euthanasia occurs where a person with the actual intention to kill unlawfully causes the death of a terminally ill patient to end pain or suffering.' This definition is consistent with that of murder, in that it includes intention, unlawfulness and causation, but is modified to include the elements of 'actual intention', which excludes 'eventual intention', and the objective 'to end pain and suffering' that is associated with euthanasia.

\section{J McQuoid-Mason}

Centre for Socio-Legal Studies, University of KwaZulu-Natal, Durban, South Africa mcquoidm@ukzn.ac.za

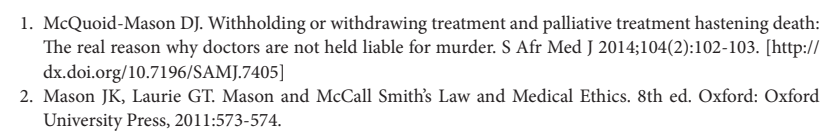

1. McQuoid-Mason DJ. Withholding or withdrawing treatment and palliative treatment hastening death The real reason why doctors are not held liable for murder. S Afr Med J 2014;104(2):102-103. [http:// dx.doi.org/10.7196/SAMJ.7405]

2. Mason JK, Laurie GT. Mason and McCall Smith's Law and Medical Ethics. 8th ed. Oxford: Oxford University Press, 2011:573-574.

S Afr Med J 2014;104(4):259-260. DOI:10.7196/SAMJ.8016 